\title{
Relational Psychoanalysis and Clinical Practice
}

\author{
John Farnsworth
}

PSYCHOTHERAPIST, DUNEDIN

\begin{abstract}
This review essay examines relational psychoanalysis by looking at examples from clinical practice and commenting on its relationship to other forms of therapeutic work. It does this through a discussion of individual and group work and by exploring the complex background out of which the relational paradigm has emerged.
\end{abstract}

\section{Whakarāpopotonga}

E aromatawaihia ana te pānga wetewete hinengaro e tēnei tuhinga arotake mā te titiro ki ngā tauira mahi a ngā mahi haumanu ka whakatau whakaaro ai mō tōna pānga ki ètahi atu momo mahi haumanu. Hai whakatutuki i tēnei, ka matapakihia te takitahi me ngā rōpū mahi me te tūhura haere i te tuarongo matatini te ūnga mai o te tauira whaiaro.

Keywords: relational psychotherapy; psychoanalysis; emergence; intersubjective; group analysis; object relations

\section{Introduction}

Relational analysis has become an influential force, particularly in recent years. It has a variety of ancestors and fellow travellers including self psychology, object relations, intersubjective and interpersonal analysis (Harris and Seligman, 2019). Growing from roots primarily in New York, it has rapidly expanded since 2001 through IARPP, the International Association for Relational Psychotherapy and Psychoanalysis. This now encompasses an increasingly global community, with chapters stretching from Greece to Aotearoa New Zealand. One of its key figures, Stephen Mitchell, "found a way", according to its first newsletter "to bring together the many contemporary schools of psychoanalysis that had heretofore been so isolated and dissociated from each other" (Aron, 2002, p. 2). In that light, this paper takes a specific focus on the question: it examines how relational practitioners describe their work in the room, and how they understand what they do.

In recent decades, the Relational field has been working out exactly what makes it distinctive, continually defining itself against other approaches. This process is far from

Farnsworth, J. (2020). Relational psychoanalysis and clinical practice. Ata: Journal of Psychotherapy Aotearoa New Zealand, 24(1), 11-27. https://doi.org/10.9791/ajpanz.2020.02 
complete and it can prove confusing for the typical practitioner in discerning what is, or isn't, considered relational. The same dilemma affects relational theorists themselves. At a key international panel, Chana Ullman introduced Interpersonalist, Relational, Object Relations and Self Psychology perspectives, commenting that relational thinking "celebrates multiplicity" (2018, p. 647). This multiplicity, she noted, was across the board in terms of psychoanalytic affiliations, therapeutic technique and emphases in perspective, all of these "bringing us closer to a truth" (2018, p. 647). Precisely what that truth might be is, of course, the question.

However, she argued (2018), relational thought also holds certain unifying questions as central:

The first axis of relational theory consists of the centrality of the analyst's subjectivity, her own conscious and unconscious embeddedness in the interaction, and the resultant shift to understanding enactments and reenactments in the intersubjective field. The second is our understanding of psychic structure as a fluid organization of multiple self-states and self/other configurations. (p. 647)

Put differently, the therapist's presence, experience and interaction in the room are central, and help make sense of the flux in any therapeutic encounter. Put this way, it becomes possible to see the debt of relational practice to earlier traditions. Pizer, for example, identifies the considerable legacy of Winnicott, Fairbairn, Klein and object relations thought, as "most useful to relational analysts as we find spontaneous, improvisational... ways to engage" (2018, p. 681). Moreover, these perceptions reveal how different relational practice is to a so-called classically analytic approach. As Estelle Shane (2018) puts it:

Intrapsychic conflict is no longer conceptualized as id/ego/superego drives and defenses. Rather, mind is perceived as more fluid, decentered, and multifocal, made up of organizations of multiple self/other configurations stemming from early object relationships. (p. 688)

The corollary is that a relational analyst is less an authority working through "accurate interpretations", and more, someone participating in "a collaborative endeavour that enhances rather than undermines mutual recognition and self-growth" (Shane, 2018, p. 688). At the same time, relationalists also have to struggle "with the problem of offering to patients our own understandings of what might be happening between us" (Shane, 2018, p. 688).

This article explores these subtleties in a number of ways. Its key approach is to draw on specific clinical moments to illustrate relational work in practice; to place these in the complicated contexts in which relational work has emerged, but also to link these to individual and group work. I illustrate this at times through the work of Robert Grossmark who, conveniently, works in both dyadic and group settings. In addition, his writing compactly illustrates the fluidity of relational practice and shows how it moves easily between relational, analytic and other traditions. Like others writers I mention, however, his work typifies the tensions and overlaps between traditions, and how they create the subtleties of relational practice. 


\section{JOHN FARNSWORTH}

\section{Opening positions}

When Ullman (2018) introduced this major panel on the state of relational analysis she commented:

The relational approach changed the way we think of our patients; it changed the way they think about us and what they expect from us. It is evident in the clinical material that we have here that we are no longer busy hiding our subjectivity, on one hand, no longer preoccupied with fighting other approaches on the other. The paradigm shift is already here, producing a liberating effect on the entire field of psychoanalysis and psychotherapy, and in turn affecting the relational perspective itself. (p. 649)

In the same issue, Jody Messler Davies (2018) outlines the same developments a little differently: "the relational position did begin as a critique of more traditional positions," she writes. Its pioneers grappled, she argues, with:

analytic neutrality and abstinence, the "problem" of the analyst's subjectivity within a purely insight-driven model of therapeutic action, the differences between a drive conflict model and a relational conflict model (p. 652)

She goes on to observe:

I think it is fair to suggest that at least part of the difficulty in proactively defining the relational position can be traced back to the very deep feelings held by Stephen Mitchell, who might easily be identified as something like the "father" of relational psychoanalysis. (p. 652)

This 'father' trenchantly opposed anything that stifled "the creative thinking of those who were drawn to relational ideas", fearing that "10 years from now people will be standing up at meetings and telling each other that their work isn't relational enough!” (quoted in Messler Davies, 2018, p. 652). Yet Messler Davies also acknowledges that "what unites relational writers who come from different psychoanalytic traditions - Freudian, Kleinian, Object Relations, Self Psychology - has more to do with the kinds of questions asked than with the particular answers offered" (2018, p. 651).

\section{Thinking and working relationally}

How does this translate to actual therapeutic practice? Seligman and Harrison (2011) give one description:

Patient and therapist are constantly communicating in facial expressions, physical gestures, vocal rhythms, and pauses and silences as well as even more subtle gestures such as the rustling of their clothes or a change of position. For example, a throatclearing may communicate stress whereas leaning forward may communicate intensified interest. In a rather ordinary encounter, the therapist greeted her patient, 
a divorced middle-aged man, in the waiting room and walked with him into the office. The patient had not yet spoken, and his facial expression was unremarkable, but the therapist detected a change. "Something's up! Something good," she remarked. The patient's face relaxed into a grin. "I’ve met someone," he said.(p. 504)

Seligman (2012) uses this passage to demonstrate how micro-observation and attachment theory can be employed to tune a therapist into making sense of interactions such as these. Interestingly, this passage is situated at the crossroads between analytic and relational approaches. As Seligman comments, "Relational psychoanalysis has been less explicit about its developmental models, importing the ambivalence toward them of its interpersonalist ancestors" (2012, pp. 499-500).

The moment itself illustrates how the translation of microscopic affect between patient and therapist is noticed and negotiated. In being negotiated, and then immediately articulated, such a casual but explicit comment from the therapist, followed by the client's immediate response, might constitute a significantly relational act. On the other hand, analysts from other traditions might engage in similar ways. The difference, then, may lie in a therapist's theoretical frame of reference and what each frame points up in this exchange. Either way, it emphasizes the ambivalence Seligman (2012) mentions towards earlier approaches and, by extension, what a particular frame tunes a therapist to pick out from this interaction.

As it happens, the vignette quoted goes on to illustrate just how much overlap, or ambivalence, there can be between approaches. Is the observation that follows purely relational? It is hard to think so:

As the patient turned to say goodbye at the session's end, however, he made an almost-unnoticeable flourish with his head and shoulders. The therapist suddenly recognized that he had made the same gesture as he had stood aside for her to enter the office at the beginning of the session. (p. 245)

Immediately, a rapid to-and-fro of transference and counter-transference emerge out of a barely grasped moment. These, themselves, are intertwined with the patient's earlier "good news". The crossroads, here, is that this work is both unobtrusive and also offered in such a way that it could be readily grasped by analytic or relational schools alike.

As clinicians, we might simply admire the acuity of the clinical work taking place here. Why worry, then, about such slight distinctions between approaches?

One answer can be found in the writing of Donnel Stern, a key relational thinker. In reframing interactions such as these in a different way, he points to how language and theory act as a lens that reorders what we apprehend as therapists. For instance, his writing might well recast this incident as the emergence of unformulated experience. Unformulated experience is a "potential meaning that has not, or not yet, come to fruition" (Stern, 2019, p. 93).We might say it is 'pre-verbal', but that is not what Stern has in mind. Rather, formulation, verbally or non-verbally, enables a fully formed meaning within a therapeutic dyad to emerge and, potentially, for therapeutic change to occur at that moment (2019, p. 7). In Seligman's example, it arises at the point the therapist recognises how the cumulative 
actions by both parties represents the emergence of a new, complex, implicit interplay between them. I return to Stern's influential and distinctive perspective later in this article, but these remarks illustrate how his different use of language reconfigures thinking within psychodynamic interaction.

Instead, I unpack another instance of relational work through a case described by Robert Grossmark.

\section{Grossmarks Unobtrusive Relational Analyst}

Grossmark builds, he says, on "a contemporary relational sensibility" (2012, p. 689). One of his explicit aims is how to engage with the most difficult areas of unarticulated suffering. Here, I draw on a much more complex instance as illustration. As he writes (2018):

For patients who do not experience themselves as existing in time and space in a continuous and coherent way, and who do not regard other human beings as whole, coherent, and separate beings, as subjects; it is too much to expect mutuality. Such patients' reality often involves confusion as to whether they are alive or dead, and whether the world, other people, and the self actually exist and can be expected to continue to exist. These damaged self-states may co-exist simultaneously with verbally adept, intellectual and related self-states. (pp.14-15)

In passing, the passage signals an attunement that is organized in part through a relational language: mutuality and self states being keys to this. As he continues :

Psychoanalytic healing and psychological growth and differentiation take hold when the psychoanalyst can unobtrusively companion the patient into areas of nondeveloped, non-related, and non-represented inner life in the register that is organic to the patient at that time. In so doing, the unrepresented and unformulated take spontaneous form and are embellished in enactment between the analytic partners and in the field. (p. 4)

Again, his language draws on a relational perspective ("unrepresented and unformulated") to foreground not only how a patient is presented differently but how a therapist's expectations and attunement may also be organised. He extends this by introducing the new concept of companioning. Companioning, he wants to show, enables the analyst not only to work unobtrusively but, potentially, to reside within these experiences together with the patient. From this, "other states and possibilities emerge spontaneously and can free the patient from the deathly grip of early toxic identifications" (2018, p. 6).

To do this work, Grossmark emphasises that he draws from across "the contemporary psychoanalytic tapestry, including relational, object relations, contemporary Freudian, British independent, self psychology, intersubjective, infant research and more” (2012, p. 630). In some ways, this echoes Seligman's broad integration mentioned earlier.Commenting on his own approach, Grossmark writes that "It seems to me that silence, quietness, patience, and not speaking the countertransference have been conflated with 'neutrality"' (2012, p. 
631). He indicates, in other words, an implicitly classical analytic stance. He goes on by referring to Winnicott's "paradoxical approach to transitional phenomena", writing:

that we continually co-construct experience in analysis and recognize that not all patients experience this or are even aware that this might be so, or even that bringing this to the patient's consciousness is always of value. I take from Winnicott $(1958 / 1965)$ that we are continually situated in the intersubjective matrix and that treatment can be allowed to unfold such that areas of psychological being that we are barely able to sense, let alone describe in words, can emerge and take shape. (p. 631)

Grossmark silently moves here from Winnicott and object relations to make an intersubjective claim about how treatment takes place. In doing so, we can see how the bridge between relational and other traditions is built. The dilemma for the reader with such a passage, is how to find the dividing line between these practices. The same comment could be applied to the Seligman passages cited earlier. How, in practice, do we discern one from the other, especially in the crucible of the therapy room?

To demonstrate his work in practice, Grossmark unpacks his seven-year work with Kyle, a case he describes in an individual paper (2012, pp. 634-641) and his recent book (2018, pp. 22-28). He describes in both how he worked:

Generally, I was unobtrusive while being totally and intimately engaged. I'd silently make connections in my own mind to myself, tracking my reverie and my thought about his psychic process, while engaging in these discussions with sincerity and real interest. My strong feeling in these times is the opposite of what one hears most frequently, across psychoanalytic approaches: it is OK for these kinds of extra-therapy interactions or enactments to occur, as long as they are talked about or analyzed after. My feeling was that it was of the utmost importance that I enter these interactions as me, unadorned; and it was equally important, that they were not talked about after. (2018, p. 26)

However, his thoughtful approach is constantly capsized by Grossmark's actual experience, as he described it in 2012:

I found myself continually confused. At first I panicked and would ask questions in a futile attempt to gain clarity, interrupting his flow of words. Explanations did not help. I learned that I had to settle into this felt world of confusion and near-psychosis, and somehow to find some way to get comfortable, or at least survive and keep my own mind intact. (p. 635)

This appears at odds with his portrayal of Kyle himself:

His speech, very articulate and full of psychological insight, came at me like a pulse, an unstoppable tsunami of word-things. His words continued to come at and into me, sometimes slamming, sometimes penetrating, and sometimes caressing. Always 
totally physical. He told me that he was struggling with deep depression for which he had been in therapy since he was a teenager. (2018, p. 21)

Grossmark himself is rapidly plunged into further confusion:

I tried to get a grip on the narrative of his and his family's life, but, as was to become so familiar to me with Kyle, I'd become so flooded and confused that coherence was impossible. I did gather that his biological father had left his mother before he was born, that there had been some unsuccessful attempts at reunion, that he had been brought up primarily by his mother and her second husband [and so on].(p. 22)

In this recounting, emergence and formulation seem a distant prospect. In addition, Kyle discloses a violent, damaging drug-filled history, takes up online sex and, later, exposes his stomach to show Grossmark the results of his liposuction surgery:

when he showed me his punctured torso I stayed within the register and content that he occupied and talked about liposuction and his doctor, without any insertion of an understanding from outside of his immediate felt experience. I silently contained my intellectual and gut reactions to this moment. (p. 24)

Tolerating this and much more, Grossmark is finally able to report the emergence of a "mutual regression", one he understands through the work of Michael Balint (1968):

Kyle could regress and bring in his deadness and not-yet-aliveness, and I found a way to tolerate the disturbances in the field of the analytic setting and in my own mind, so that this could be a productive experience. (2012, p. 639)

Grossmark emphasises that his unobtrusiveness was key to this, where a "mutual regression required my availability to a mutual regulation", adjusting "to the unusual rhythms and outlines of Kyle's way of being: his nonappearance in sessions, his bouts of incessant and pressured speech, and above all his unique signature and idiom that infused my mind and the total 'field' of our work' (2012, p. 640). Mutual regression and mutual regulation became, referring to Lachmann and Beebe (1996), "the therapeutic action itself, ultimately promoting the growth of Kyle's own sense of aliveness and self” (2012, p. 641).

What is striking in these passages, apart from the intensity of the work, is how reliant they are on a foundation in object relations to sustain Grossmark; this is particularly with the concept of regression, which draws on Balint and object relations. Yet, the passages are also expressed in a relational language (the field, enactment, mutual regulation), sometimes in the same sentence as classic analytic terminology (regression) rooted in a depth psychology (Staude, 1976).

On this compressed account, it would be possible to read Grossmark's thinking as either theoretically conflicted or as integrative. Having engaged myself in a colloquium with Grossmark featuring the 2012 paper, it is clear his intention is integrative. At the same time, the writing demonstrates the tremendous strain in having to draw together such disparate 
traditions, formulations and perspectives. In a sense, these are the stakes which confront the relational/intersubjective position: to show that it offers the daily working therapist a reliable toolkit with which to engage the most difficult experiences with patients and clients. Grossmark's emphasis is on unobtrusive relating as the key, along with the notion of close, attentive companioning. The dilemma here is that a wide range of theoretical modalities have long claimed to do the same thing, albeit in a different language.

\section{The Relational Perspective}

The dilemma is inherent not just in how relational practice attempts to define what makes it distinctive, but in competing understandings of what it actually is. This is further complicated by the ongoing innovations within the area itself. In some cases, these innovations translate or transform existing analytic understandings. I will return to this issue of transformation below.

In relational thinking, Donnell Stern (1983, 2013a, 2013b, 2013c, 2019), for example, transforms a number of terms, such as the analytic field or unformulated experience; Benjamin (2004) reconsiders the dyad as an analytic third; Ringstrom (2018) rethinks proto emotions and transference in terms of information theory; the notion of drive becomes either subdued or reconfigured (Mills, 2005, 2018); there is an engagement with non-linear systems theory (Seligman, 2012). And so on. Taken together, these amount, as Fosshage (2018) notes, to attempts to develop new models of mind. To do so, relational work draws on new findings in neuroscience, trauma, infant studies and other fields, applying them within dyadic, couple and group work.

Alongside such innovation, there are starkly differing accounts, from inside and outside the field, of what is being undertaken, let alone how successful it is. For example, the German analyst Peter Pothoff (2017, p.363) comments that "there are many nuances of intersubjective theory", going on to group these "nuances" together, including Intersubjectivists (Stolorow et al.,1992), interpersonal psychoanalysis (Levenson,1983), post-Bionian field theory (Ferro, Civitarese and Ogden, 1994) and relational psychoanalysis.

What that means in practice, Potthoff suggests, is that, "in contrast to traditional psychoanalytic ideas", therapy is "one of mutual influence and regulation" that equally affects both parties. This offers the possibility for the "progressive unfolding of a new, less pathogenic object relation" (2017, p.364).

Jon Mills (2005, 2018, 2020), in a series of forceful critiques, is far less equable, and insists that relational practice makes claims that are unsustainable. Although he praises relational analysis as "a breath of fresh air" (2018, p. 334) he upends the relational apple cart by asserting that "it was Freud who first explained how relationality was made possible through the transformation of the drives" and that "relational concepts were implicit in Freud's early work all along" (2018, p. 332). In short, a relational perspective is hardly new, and in fact, originated from the very theory of drives that relationists disclaim. As he asserts, there are "invented schisms between classical and relational viewpoints" (2018, p. 333). These, and a range of other criticisms around therapeutic excess, self-disclosure, shortcomings of dyadic mutuality, and much else are disputed by Steve Kuchuk (2018) and others (see Mills, 2020). Kuchuk points out that Mills has conflated small and big ' $R$ ' relationists, blurred relational and intersubjective 


\section{JOHN FARNSWORTH}

positions, made "a number of assertions that seem not to be mutually exclusive" (2018, p.346) and so on. This, however, also leaves the impression that relational thinking is increasingly opaque and hard for a lay reader to fathom.

In practice, each commentator is trying to define a complex history, now spanning decades, as relational analysis attempted to distinguish itself from similar, foregoing or competing approaches. This is not the place to rehearse these (see, for example, Mascialino, 2008 , for one such account).

Enough to say that 'Interpersonalist' is the broad term used to title two large collections, edited by Stern and Hirsch, of interpersonal/relational writing (2017a, 2017b). Like Core Competencies in Relational Psychoanalysis (2018), these volumes illustrate the unfolding development of a canon of relational practice alongside the sheer, unfinished complexity of the larger relational project. As Miller writes, "Interpersonalism has always been in conceptual flux, disagreeing, integrating, refining, and forging ahead generationally" (2019, p. 237). Noting its earliest roots in the relationally-attuned Ferenczi against the analytic Freud, he notes several seminal moments: the "scholastic fault-line" emerging through the 1983 publication of Greenberg and Mitchell's contemporary 'classic', Object Relations in Psychoanalytic Theory, the influence of the Boston Change Process Study Group and "the evolution of Interpersonalism into Relationism" with the rise of late 1990s' identity politics (2019, pp. 234-235).

These alternative perspectives and terms suggest we are witnessing not simply complicated theoretical positionings but political struggles, too. As Raymond Aron puts it, "Words and terms quickly take on the role and status of political flags for particular schools of thought" (2019, p. 93). Their usage or absence "identify the speakers as insiders and outsiders" (Aron, 2019, p. 93) to any given tradition.

Yet, there is more here than simply analytic politics. As Donnell Stern's work illustrates, relational thinking is an ongoing attempt to articulate an alternative analytic language.

\section{Donnel Stern and Unformulated Experience}

Donnel Stern describes a moment with Robert, a patient who suddenly reaches an insight: that "Freud's own psychic life must have been the most important source of inspiration for his ideas" (Stern, 2019, p. 62). This insight relates, of course, to Robert's own psychic life. This moment has come after much work, silence, inarticulacy and frustration, yet Stern's following question is unexpected:

Can we say that this thought was somehow already "there" inside Robert, "in" his unconscious, just waiting for him to acknowledge it? Of course not. Robert formulated this thought in the moment he spoke it. It was an unbidden construction, a very particular interpretation created in the context of a very particular time and set of circumstances; and it surprised him. (p.62)

Stern's work is central to understanding how important strands of relational thought have developed. As Aron and Mitchell (1999), the editors of Stern's (1983) article, summed it up: 
The implications of the shift from the Freudian unconscious to the relationally unformulated are enormous and still being worked out. Stern's work anticipated and also helped bring about many later developments in relational theorizing: the shift from an emphasis on repression as the prototypical defense to dissociation; the importance of language in the construction of experience; the linkage between an interpersonal understanding of the contextual nature of mind and constructivism in cognitive psychology. (1999, pp. 78-79)

Stern $(2015,2019)$ acknowledges his orientations are quite different to those typical of psychoanalysis. They reveal considerable debts to Harry Stack Sullivan, but increasingly to what Masler (2014) calls the Interpretative turn: the hermeneutics of Hans-Georg Gadamer, the existential philosophy of Heidegger and, latterly, Merleau-Ponty. Put together, this constitutes an alternative and sometimes strange world for a psychotherapist. As an example, Stern comments that:

Sullivan did not use the term "transference". He preferred "parataxic distortion", by which he meant the attribution of meanings in the here-and-now to another person, meanings that cannot be specified and that are, in fact, not even suspected by the person who creates them. (2019, p.3)

These re-descriptions quickly become disorienting because of the different frame of reference from which Stern is working. As Masler notes, "For Stern, psychoanalysis is no longer an archaeological project. It no longer involves rebuilding a hidden past, just as in Gadamer's hermeneutics” (2014, p. 75). But what does this mean? For Gadamer, or Buber, the act of conversation or dialogue is fundamental: as it unfolds, the horizon around it constantly changes, shaped by the language in use and by the oscillating influence of each speaker on the other. So, "for Stern", Masler writes, "dialogue is an essential of therapeutic change" (2014, p. 142). Consequently, "psychotherapy is an emergent process" (Stern, 2013c, p. xv) because, in a genuine conversation, we cannot anticipate where it will go nor how we will experience ourselves or the other: spontaneity becomes integral to the relational process (Masler, 2014).

In this context, the concept of the field is critical for Stern: conversation always emerges from an interpersonal field, one that enables unfolding experience to be formulated from the interpersonal exchanges that take place within it (Stern, 2013d). For Stern (2013d, 2019), the field shifts away from a Freudian emphasis on disinterring the past "and toward understandings based on present events as the outcomes of contemporary configurations" (Stern, 2013a, p. 634). The field is a co-creation; it allows: "symbolizing experience in the here and now, experience that had been felt but could not be thought," so that it has "a therapeutic impact by enlarging the domain of the dialogue between patient and analyst" (2013a, p. 635).

Stern's work illustrates how relational thought draws deeply on a different philosophical tradition than Freud's. Consequently, the therapist becomes immersed in, not separate from, the shared experiential world with the patient. Each moment becomes potentially dynamic: a slowly unfolding encounter between two parties through complex verbal and non-verbal communication that reveals glimpsed, or explicit, self-states. 


\section{JOHN FARNSWORTH}

If this is dyadic work, do these precepts still hold in the context of groups? Much relational thought, as with Stern, turns on a two-person interaction, but groups provide a quite different environment in which to consider relational perspectives.

\section{Groupwork and Relational Thinking}

A wasp arrives in the middle of an established group, and is promptly killed by the group leader. This provides an unexpected opportunity to examine "the intersection of group analytic thinking and relational psychoanalytic conceptualization" (Raufman, 2019, p. 197). The opportunity is taken in a 2019 edition of Psychoanalytic Dialogues between the group analyst, Ravit Raufman, and her commentators Grossmark and Haim Weinberg. Raufman vividly describes the moment:

All of a sudden, the wasp flew extremely close to one participant, who was pregnant. In response, I automatically, and in a determined manner, stood up, stamped on the wasp, and killed it. From that moment on, a drastic change occurred within the group's process. (p.187)

The drastic change refers to what had previously been a glutinous group process, as Grossmark summarises it:

she found herself in a painful impasse with a group that she found unwilling to face the aggression, rivalry, and envy that she believed were silently dominating the process of the group and leading to prolonged silences, missed sessions, and a general "[refusal] to cooperate". (p. 216)

After the wasp, however, both Raufman and the group members could "own their own aggression" and "finally work authentically and productively: the group finally came to life" (Grossmark, 2019, p. 216).

Yet, Raufman, Weinberg and Grossmark each make a different sense of this enactment. For Raufman (2019, p. 234), these "difficult days" point to the limitations of group analytic thinking to understand aggression in this context. For Weinberg (2019, p. 229), it highlights the larger sociocultural matrix in which we comprehend aggression. For Grossmark (2019), it is an opportunity for theory:

I suggest that Raufman's difficult days are emblematic of being caught between older, more classically based theory that inheres in much group therapy and theory and the recent embrace of relational concepts. (p. 217)

Consequently, in relational thinking:

Aggression is not simply regarded as a force, a drive to be reckoned with, but is a feature of an emergent intersubjective field and the engagements, conscious and unconscious, that compose that field. (p. 218) 
At this moment of mutual enactment, Grossmark sees:

the aliveness of the conductor. She was finally able to join the group in the register that they had inhabited all along, of unthought, motoric action, the enactive register. (p. 223)

How, then, is aggression understood by Grossmark in this context? He writes:

a wasp stings only when it is engaged in a particular relational moment, if you will: that is, when it believes it is under attack, which unfortunately often happens when humans wave their arms about in the presence of a wasp. (p. 218)

What do we make of this? Raufman and Weinberg discuss how 'classical' group analysis, despite shortcomings, currently offers a much more developed theory of group enactments, including aggression, than relational thought. It can also more persuasively locate aggression, envy and hostility within broad sociocultural contexts than relational thinking. Tubert-Oklander echoes this in his detailed comparison of relational and group analytic work:

The fact that most present-day relational analysts have focused on bipersonal ("individual") therapy and lack a group-analytic training and experience has made it difficult for them to recognise that many of their relational concepts have been previously introduced and developed by group analysts. (2013, p. Xviii)

For instance, what seems to go missing in these group encounters is the question of impulse or reaction: what prompted either wasp or human to act as each did? Grossmark presents it as contiguity: each was close to the other. To suggest they were somehow "in relationship" at this point begs the question. It doesn't answer the larger question of motive: what motivated each party to act as it did? One answer might be simple fight/flight, but that only returns us to internal or innate responses. Does it suggest instead that aggression, whilst clearly acknowledged, is not fully resolved within a relational framework?

One could understand this as an important moment of translation: Freud's initial concepts of aggression are translated into the relational language of aliveness; at the same time, the underlying issue of drive, of which aggression is a key component, is elided: it is largely absorbed into the commentary. In this context, the reader is left unclear about what constitutes a relational theory of aggression, whilst the role of drives drops from sight.

\section{Implications}

This discussion suggests there are a number of unresolved questions for the relational perspective. For example, if one focuses on the emergent moment and its relational field, how does one incorporate the longitudinal, intergenerational history in which it is situated? In a sense, relational practice constantly confronts both problems. On the clinical front, it develops entirely new set of tools and languages to describe and redescribe areas of 


\section{JOHN FARNSWORTH}

interpersonal experience in the therapeutic setting. At the same time, as Seligman notes, it has to rely on existing non-relational work developed in other areas of psychoanalysis. It also runs the risk of being recaptured by them. Stern (2019), for instance, is very clear about favouring an interpretative over a 'scientific' approach to analysis to confront biomedical assumptions that have long bedevilled psychoanalysis.

The working solution, adopted by Grossmark, Seligman and many other relational writers is to incorporate existing psychoanalytic literature as needed, as I described earlier. This also amounts to a way of recuperating analysts' own intergenerational traditions (Grossman, 1992) rather than totally discarding or reinventing them. Of course, this then runs a different risk: of becoming merely another therapeutic 'flavour', competing with all the other variants in the field.

In every case, we might agree, as William Grossman (1992) observes, that therapeutic work continually involves acts of translation or transformation. This is what I suggested earlier with the relational tradition. Grossman, formerly influential but now little-read (Wilson, 2009), explores this process in detail. He emphasises (1992) that every moment in the room involves a continuous process of translation, compression and transformation of raw therapeutic material to produce any sense for the therapist of "what is going on here". This is typified in the relational instances cited earlier. Moreover, Grossman demonstrates that the concept of translation was itself one of Freud's key contributions (Grossman, 1992): it was "Freud's mode of thought" (Reed, 2009, p. 9) [emphasis in the original].

Reed summarises Grossman's (1992, p. 56) observations this way:

we require a way of moving from the self-observation of the analyst when in the presence of a self-observing patient to an understanding of what our self-observation reveals about the patient and then, more widely, about many patients. This effort then constitutes a translation... (p.42)

Yet another translation takes place in moving between different systems of thought or registration (Reed, 2009, p. 43), as illustrated in the analytic and relational systems discussed here.

Where relational writers mobilise different therapeutic registers these, from Grossman's perspective, are typical of "thought communities" (Grossman, 2006, p. 87).Such communities unavoidably create a complex internalised authority in therapists, regardless of which system they adhere to (Grossman, 2006). As Wilson (2009, p.14) comments,

An individual analyst's relationship to authority is subtle and finds powerful expression in conflicts about how he can justify interventions to himself.

It is these communities, including those of relational theorists, which produce, in effect, different therapeutic objects: 'aggression' or 'liveness' typifies this and points to different ways of articulating the intersubjective worlds being generated. But if Grossman is correct, these thought communities are also the justification and the authority for one intervention over another, be it relational or analytic.

All these paradoxes are far from unique to analysis. On the contrary, the social sciences 
have long traced tradere: the oscillations between tradition and innovation, translation and transformation that have roots in literary, biblical and historical studies (Schmidgen, 2014, pp. 4-14). Like them, the tradition beginning with Freud is constantly reworked, stabilised then transformed again, with all the schisms and loyalties in attendance. It seems hard to imagine that the relational turn can escape these; indeed, the cited examples suggest otherwise.

Does it require us, then, to adjudicate between the claims of the relational over other approaches? In this context, that seems a counterproductive decision. Indeed, this may risk recapitulating the very therapeutic political wars to which Raymond Aron referred. Rather, in the daily therapeutic hothouse, it may be better to follow Grossman, continually investigating and reflecting on how our different registers of experience, therapeutic identifications and clinical engagement are manifested as the work unfolds.

\section{Conclusion}

There is a vast range of relational writing untouched by this review. Messler Davies points to "a first generation of relational writers" which, including herself, stretches across Aron, Mitchell, Hoffman, Ghent, Harris, Benjamin, Altman, Dimen, Bromberg, Stern and Ehrenberg (Messler Davies, 2018, p. 652). Consequently, the issue of the analytic third, of gender, sexuality or race, working with couples and many other topics can find little place here, let alone larger sociocultural or intergenerational issues.

More to the point, perhaps, relational thinking is, itself, an emergent enterprise: one attempting to secure a place within the highly competitive, discursive environment of psychotherapy. This may frame Blechner's (2018) observation:

Is the relational school of psychoanalysis post drive theory? I would say no, or at least I am not. I think drive theory needs revising but not dismissal. It may certainly be argued that the Freudians went too far in focusing on sex and aggression as human motivators and did not pay enough attention to other human needs, such as intimacy, security, prestige, attachment, and relatedness. But if they went too far, the relational world may have gone too far in the opposite direction. (p. 675)

Whether we agree or not, it is clear that relational thinking is both influenced and influencing in wider therapeutic contexts. To recall Messler Davies' comment, what unites relational writers is "more to do with the kinds of questions asked than with the particular answers offered” (2018, p. 651). 


\section{JOHN FARNSWORTH}

\section{References}

Aron, L., \& Mitchell. S. (Eds.). (1999). Relational psychoanalysis: The emergence of a tradition. Hillsdale, NJ: The Analytic Press.

Aron, L. (2002). Launching the IARPP e-Newsletter. IARPP eNEWS: A Quarterly Electronic Periodical of the International Association for Relational Psychotherapy and Psychoanalysis, 1(1), 1-3.

Aron, L. (2019). Discussion of "Bread and roses: Empathy and recognition". Psychoanalytic Dialogues, 29(1), 92-102.

Balint, M. (1968). The basic fault. London, England: Tavistock.

Barsness, R. (Ed.). (2018). Core competencies of relational psychoanalysis (1st ed.). London, England: Routledge.

Benjamin, J. (2004). Beyond doer and done to: An intersubjective view of thirdness. Psychoanalytic Quarterly, 73, 5-46.

Blechner, M. (2018). Data, dreams, and drives: Interpersonal and relational innovations in perspective. Psychoanalytic Dialogues, 28(6), 670-678.

Fosshage, J. (2018). Discussion of three dimensional field theory. Psychoanalytic Dialogues, 28(4), 397-402. https://doi.org/10.1080/10481885.2018.1482129

Greenberg, J., \& Mitchell, S. (1983). Object relations in psychoanalytic theory (1st ed.). Cambridge, MA: Harvard University Press.

Grossman, W. (1992). Hierarchies, boundaries and representation in a Freudian model of mental organization. Journal of the American Psychoanalytic Association, 40, $27-62$.

Grossman, W. (2006). Some perspectives on relationships of theory and technique. In P. Fonagy \& J. Canestri (Eds.). Psychoanalysis: From practice to theory (pp. 87-102). London, England: Whurr.

Grossmark, R. (2012). The unobtrusive relational analyst. Psychoanalytic Dialogues, 22(6), 629-646.

Grossmark, R. (2018). The unobtrusive relational analyst. New York, NY: Routledge.

Grossmark, R. (2019). Difficult days: The continuing evolution of relational group analysis: Discussion of "Taking the sting out: manifesting aggression and containing difficult states in a relational group psychotherapy”. Psychoanalytic Dialogues, 29(2), 216-225.

Harris, A., \& Seligman, S. (2019). Historical and political factors in the inception of relational psychoanalysis. Psychoanalytic Inquiry, 39(2), 136-137.

Lachmann, F. M., \& Beebe. B. (1996). Three principles of salience in the organization of the patient-analyst interaction. Psychoanalytic Psychology, 13, 1-22.

Mascialino, R. (2008). Critical appraisal of relational approaches to psychoanalysis. Ph.D. Dissertation, University of Texas, TX. https://repositories.lib.utexas.edu/handle/2152/18184

Masler, D. (2014). The self of the field and the work of Donnel Stern. Ph.D. Dissertation, Antioch University, OH. https://etd.ohiolink.edu/pg_10?::NO:10:P10_ETD_SUBID:100559

Messler Davies, J. (2018). The "rituals" of the relational perspective: Theoretical shifts and clinical implications. Psychoanalytic Dialogues, 28(6), 651-669.

Miller, I. (2019). Donnel B. Stern and Irwin Hirsch (Eds.): The interpersonal perspective in psychoanalysis, 1960's-1990's: Rethinking transference and countertransference; AND Further developments in interpersonal psychoanalysis, 1980's-2010's; Evolving interest in the analyst's subjectivity. The American Journal of Psychoanalysis, 79(2), 234-39.

Mills, J. (2005). A critique of relational psychoanalysis, Psychoanalytic Psychology, 22(2), 155-188.

Mills, J. (2018). Critique of relational psychoanalysis. In R. E. Barsness (Ed.). Core competencies of 
relational psychoanalysis, (1st ed.), pp. 321-341. New York, NY: Routledge.

Mills, J. (2020). Debating relational psychoanalysis: Jon Mills and his critics. New York, NY: Routledge.

Pizer, S. (2018). Where all the ladders start: A clinical account of object relations legacies, selfstates and analytic process. Psychoanalytic Dialogues, 28(6), 679-686.

Potthoff, P. (2017). Group-analytic practice today: Intersubjective perspectives and the relational paradigm. Group Analysis 50(3), 361-75.

Raufman, R. (2019). Taking the sting out: Manifesting aggression and containing difficult states in a relational group psychotherapy. Psychoanalytic Dialogues, 29(2),197-215.

Reed, G. S. (2009). "In the same way a poem contains the alphabet": The significance of translation in William I. Grossman's Freud. Journal of the American Psychoanalytic Association, 57, 37-60. Https://doi.org/10.1177/0003065108329879

Ringstrom, P. (2018). Three dimensional field theory: Dramatization and improvisation in a psychoanalytic theory of change. Psychoanalytic Dialogues, 28(4), 379-396.

Schmidgen, H. (2014). Bruno Latour in pieces: An intellectual biography (G. Custance, Trans.; 1st ed.). New York, NY: Fordham University Press.

Seligman, S. (2012). The baby out of the bathwater: Microseconds, psychic structure, and psychotherapy. Psychoanalytic Dialogues, 22(4), 499-509.

Seligman, S., \& Harrison, A. (2011). Infant research and adult psychotherapy. In G. O. Gabbard, B. Litowitz, \& E. Williams (Eds.), American Psychiatric Association textbook of psychoanalysis, (2nd ed., pp. 239-252). Washington, DC: American Psychiatric Publishing.

Shane, E. (2018). A relational self psychological approach to the clinical situation. Psychoanalytic Dialogues, 28(6), 687-695. https://doi.org/10.1080/10481885.2018.1538754

Staude, J. (1976). From depth psychology to depth sociology: Freud, Jung, and Lévi-Strauss. Theory and Society, 3(3), 303-38.

Stern, D. (1983). Unformulated experience: From familiar chaos to creative disorder. Contemporary Psychoanalysis, 19, 71-99.

Stern, D. (2013a). Field theory in psychoanalysis, Part 2: Bionian field theory and contemporary interpersonal/relational psychoanalysis. Psychoanalytic Dialogues, 23 (6), 630-645. https://doi.or g/10.1080/10481885.2013.851548

Stern, D. (2013b). Philip, me, and not me: A personal and professional introduction to the special issue celebrating the work of Philip Bromberg. Contemporary Psychoanalysis, 49(3), 311-322.

Stern, D. (2013C). Psychotherapy is an emergent process: In favor of acknowledging hermeneutics and against the privileging of systematic empirical research. Psychoanalytic Dialogues, 23(1), 102-15.

Stern, D. (2013d). Relational freedom and therapeutic action. Journal of the American Psychoanalytic Association, 61(2), 227-256. https://doi.org/10.1177/0003065113484060

Stern, D. (2015). Unformulated experience: From dissociation to imagination in psychoanalysis. London, England: Routledge.

Stern, D. (2019). The infinity of the unsaid: Unformulated experience, language, and the nonverbal. London, England: Routledge. https://doi.org/10.4324/9780429468087

Stern, D., \& Hirsch, I. (Eds.). (2017a). The interpersonal perspective in psychoanalysis, 1960's-1990's: Rethinking transference and counter transference. New York, NY: Routledge.

Stern, D., \& Hirsch, I. (Eds.). (2017b). Further developments in interpersonal psychoanalysis, 1980s-2010s: Evolving interest in the analyst's subjectivity. London, England: Routledge. https:// doi.org/10.4324/9781351265409 


\section{JOHN FARNSWORTH}

Tubert-Oklander, J. (2013). Theory of psychoanalytical practice: A elational process approach. London, England: Karnac Books.

Ullman, C. (2018). Introduction to panel: The rituals of relational psychoanalysis. Psychoanalytic Dialogues, $28(6), 647-650$.

Weinberg, H. (2019). Discussion of "Taking the sting out: Manifesting aggression and containing difficult states in a relational group psychotherapy”. Psychoanalytic Dialogues, 29(2), 226-232.

Wilson, A. (2009). Theorizing about theorizing: An examination of the contributions of William I. Grossman to psychoanalysis. Journal of the American Psychoanalytic Association, 57(9), 9-36. https://doi.org/10.1177/0003065108330523

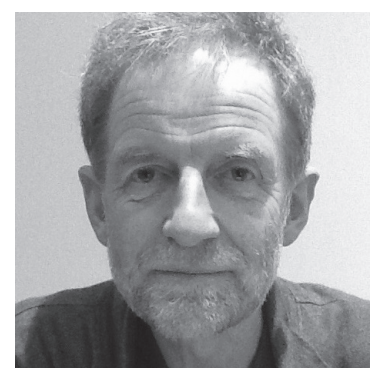

John Farnsworth is a registered psychotherapist in private practice in Dunedin. He has been in a member of NZAP for many years and continues to work as an examiner and moderator for the Advanced Clinical Practice qualification. Having a long background in psychodrama, he has also published extensively in the social sciences, predominantly in the areas of sociology, anthropology and social methods. Contact email: johnf@earthlight.co.nz 